\title{
THE EFFECT OF ENDURANCE EXERCISE ON BONE DIMENSIONS, COLLAGEN, AND CALCIUM IN THE AGED MALE RAT
}

\author{
Robert E. Beyer*, Jessie C. Huang**, and Gilbert B. Wilshire*** \\ Laboratory of Chemical Biology, Department of Cellular and Molecular Biology, \\ Division of Biological Sciences, The University of Michigan, Ann Arbor, MI 48109-1048
}

\begin{abstract}
Sixteen weeks of a relatively mild running program, started at 22 months of age, lowered the body weights of 26-month-old male rats to the level of 9-month-old rats and increased the weights and the collagen densities of hind limb bones to levels greater than those of 9-, 22-, and 26-month-old sedentary rats. The densities $\left(\mathrm{g} / \mathrm{cm}^{3}\right)$ and the calcium densities $\left(\mathrm{mg} / \mathrm{cm}^{3}\right)$ of the hind limb bones decreased with age and were restored to the 9-month level by training the elderly rats to run. These data suggest that exercise is capable of inducing a compensation for, or a reversal of, age-associated bone loss (osteoporosis) and restoring the bone mineral content in aged rats to the level of those of mature young adult animals.
\end{abstract}

\section{INTRODUCTION}

ONE OF the most consistent physiological changes that accompanies aging in vertebrates is a progressive decrease in bone mineral content, strength, and resistance to fracture. Such changes are common in most human populations and types of bone (Garn, 1970; Avioli, 1981) and the susceptibility to bone fracture appears to be directly proportional to the degree of bone loss (McMillan, 1978). Bone mineral decreases at a rate of between 0.75 and $1 \%$ per year beginning at age $35-45$ for women and $0.4-0.5 \%$ per year starting at age 50-55 for men, resulting in a 50-fold increase in hip fracture between 40 and 70 years of age (Chalmers, 1970). In humans with senile osteoporosis, fractures are most commonly associated with the radius, ulna, femoral neck and vertebral column (Arnold et al., 1969) and may occur spontaneously or as the result of mild trauma (Alffram and Bauer, 1962). Complication from fractures in postmenopausal women has resulted in a mortality rate of 15 to $30 \%$, with an estimated annual cost greater than 1 billion dollars (Avioli, 1981). The emotional, medical, and economic costs related to bone deterioration are enormous and will surely become greater as the number of elderly continues to increase.

*To whom reprint requests should be addressed.

**Present address: Stanford University School of Medicine, Stanford, CA 94395.

***Present address: Department of Microbiology, Rutgers University, New Brunswick, NJ 08903.

Correspondence may be addressed to Dr. Robert E. Beyer, Department of Biochemistry, Arrhenius Laboratory, University of Stockholm, S-106 91 Stockholm, Sweden.

(Received 30 June 1985, Revised 15 May 1985, Accepted 11 October 1985) 
Although there appears to be general agreement that some bone loss invariably accompanies aging (Albanese et al., 1969; Cassuccio, 1962; Garn et al., 1966, 1967, 1969; Goldsmith et al., 1971; Rose, 1970; Smith, 1967; Smith et al., 1981b; Urist, 1962), the etiology and mechanism are still speculative and methods employed for prevention and treatment have met with mixed success (Smith et al., 1981b; Avioli, 1977; Montoye et al., 1976). Of all the treatment modalities employed for osteoporosis, physical activity has received the least support, despite reports that in athletes and physical laborers bone hypertrophy related to their specific activities occurs (Smith, 1981; Montoye et al., 1980; Krølner and Toft, 1983; Smith et al., 1981b) and that exercise may stimulate bone accretion in humans (Mazess and Whedon, 1983; Krølner et al., 1983; Brewer et al., 1983; Oyster et al., 1984; Williams et al., 1984) and rodents (Bell et al., 1980; Saville and Whyte, 1969).

Most studies on senile osteoporosis have focused on females because of their earlier development of symptomatology. However, an increase in the incidence of osteoporosis in males may be expected as the extension in life expectancy results in an elevation in the population of elderly men. In order to gather additional information on the ability of endurance exercise to prevent or reverse osteopenia in the aged male animal, we have analyzed the effect of a relatively mild regimen of endurance training on the physical dimensions, as well as calcium and collagen contents, of hindlimb bones of elderly male rats and have compared such values to those of age-matched and middle-aged sedentary control groups.

\title{
MATERIALS AND METHODS
}

\begin{abstract}
Animals
Retired male breeder Sprague-Dawley rats****, designated $\mathrm{Cr} 1: \mathrm{COBS}^{[R]} \mathrm{CD}^{[R]}(\mathrm{SD})$, were obtained from Charles River Breeding Laboratories (Portage, MI) at 9 to 10 months of age and housed singly in the Animal Care Facility of the Division of Biological Sciences, University of Michigan, in a room segregated from other species and maintained at $22^{\circ} \mathrm{C}$ on a $12 \mathrm{~h}$ light-dark cycle. All animals received Purina Laboratory Rat Chow containing $1.01 \%$ calcium and $0.74 \%$ phosphorus and water ad libitum. Approximately $85 \%$ of the rats in our aging colony survive to 26 months of age. Four groups of rats, selected at random from our aging colony, were prepared: (a) 9-month-old sedentary, (b) 22-month-old sedentary, (c) 26-month-old sedentary, and (d) 26month-old endurance-trained for 4 months. Sedentary animals were handled by laboratory personnel for several minutes each, 5 days per week, in order to approximate the degree of handling of the endurance-trained group. Because it was our intent to study the interaction of age and exercise, animals that showed pathology or unexplained weight loss were excluded from participation in these experiments.
\end{abstract}

\section{Animal training}

The exercise training protocol was similar to that described previously (Starnes et al., 1983a,b). A group of 22-month-old rats was introduced into a protocol consisting of running 5 days per week for 16 weeks in a 10-channel, motor-driven treadmill (Quinton Instruments, Seattle, WA). Throughout the exercise program, the angle of incline of the treadmill was $8^{\circ}$ and the temperature in the exercise room was maintained at $19^{\circ} \mathrm{C}$. The first exercise session consisted of running the rats for 10 minutes at $11 \mathrm{~m} / \mathrm{min}$. On each succeeding session for the next 2 weeks, the duration and speed were increased until the rats were running for 40 minutes at $22 \mathrm{~m} / \mathrm{min}$. For the remainder of the training period, the rats ran an average of 35 minutes each day.

****Personal contact between the first author and the manager of the local rodent breeding facility enabled us to purchase retired breeders of known birth dates for these studies. 


\section{Chemicals}

All chemicals used were of analytical grade and were obtained from Sigma Chemical Co. (St. Louis, MO) except for $p$-(dimethylamino)-benzaldehyde obtained from J.T. Baker Co. (Phillipsburg, NJ) and murexide (acid ammonium purpurate) from Fisher Scientific Co. (Pittsburgh, PA).

\section{Tissue preparation}

All animals were anesthesized with sodium pentobarbital and gastrocnemius, quadriceps, and cardiac muscles were removed and used for other purposes (Beyer et al., 1984). Carcasses were stored frozen in air-tight containers until investigators were available for bone analyses (between 3 and 4 months), when right and left femurs and tibias were removed. After mechanical removal of most of the soft tissue, the bones were cleansed thoroughly of adhering tissue by the domestic beetle, Dermestes vulpinus. Bones were then washed with distilled water for 5 minutes, immersed in $10 \% \mathrm{NaCl}$ for $\mathbf{4 8}$ hours, and rinsed again in distilled water to remove any traces of adhering connective and adipose tissue.

\section{Physical measurements}

Bone volume was determined according to Archimedes' Principle ( $F=p g V$ ) by degassing the bone in distilled water in vacuo for 60 minutes, obtaining the buoyancy force from the difference in the weight of a beaker of distilled water, with and without the bone immersed, while suspended by a fine copper wire and calculating the volume of the bone essentially as described by Dequeker and Merlevede (1971). Density was calculated as dry weight/volume. This parameter should not be confused with the numerical value obtained with X-ray densitometry; the latter technique derives values more closely related to porosity of bone. Lipid was extracted from bones by the Soxhlet apparatus with petroleum ether $\left(30-60^{\circ} \mathrm{BP}\right)$ for 60 hours. Fat-free dry weight was obtained after dehydrating the bone in vacuo at $108^{\circ} \mathrm{C}$ for 60 minutes.

\section{Chemical analyses}

Bones were prepared for calcium analysis according to Kenny et al. (1958). Calcium was analyzed in femurs either with a Perkin-Elmer Model 272 Atomic Absorption Spectrophotometer (Perkin-Elmer Corp., Norwalk, $\mathrm{CT}$ ), using the method described in the manufacturer's handbook, or colorimetrically using the EDTA-murexide method of Munson $e t$ al. (1955) as refined by Ohnishi and Ebashi (1964). The two methods yielded comparable results. Collagen content of finely crushed tibias were determined by analyzing for hydroxyproline essentially according to Miyada and Tappel (1956), with the acid hydrolysis procedure of Neuman and Logan (1950), the modifications suggested by LeRoy (1967), and the corrections suggested by Dequeker and Merlevede (1971). The terms calcium density and collagen density are defined as $\mathrm{mg}$ calcium $/ \mathrm{cm}^{3}$ and $\mathrm{mg}$ collagen $/ \mathrm{cm}^{3}$ bone, respectively.

\section{Statistical analysis}

All data obtained were analyzed by a univariate one-way analysis of variance (ANOVA) using the Michigan Interactive Data Analysis System (MIDAS) developed by the Statistical Research Laboratory of The University of Michigan. Inferences about the significance of the differences between means, as well as conservative Scheffe allowances, were derived from such values.

\section{RESULTS}

The group of rats participating in the exercise program lost $10 \%$ of their body weight during the first 7 weeks of the program $(P<0.001)$, after which their weights remained relatively stable (Beyer et al., 1984). At the end of the 16 weeks of exercise the rats in the elderly trained group weighed $16.1 \%$ less than their age-matched sedentary controls $(P<0.0001)$. The mean body weight of the 26 -month-old trained group did not differ from that of the 9-month-old control group $(P=0.7125)$. The continual weight gain of this strain of Sprague-Dawley rat over its life span has been documented previously (Farrar et al. 1981; McCafferty and Edington, 1974).

Training also resulted in an increase in the dry and fat-free dry weights of femurs and tibias to levels equivalent to or greater than the 9-, 22- and 26-month-old sedentary rats 


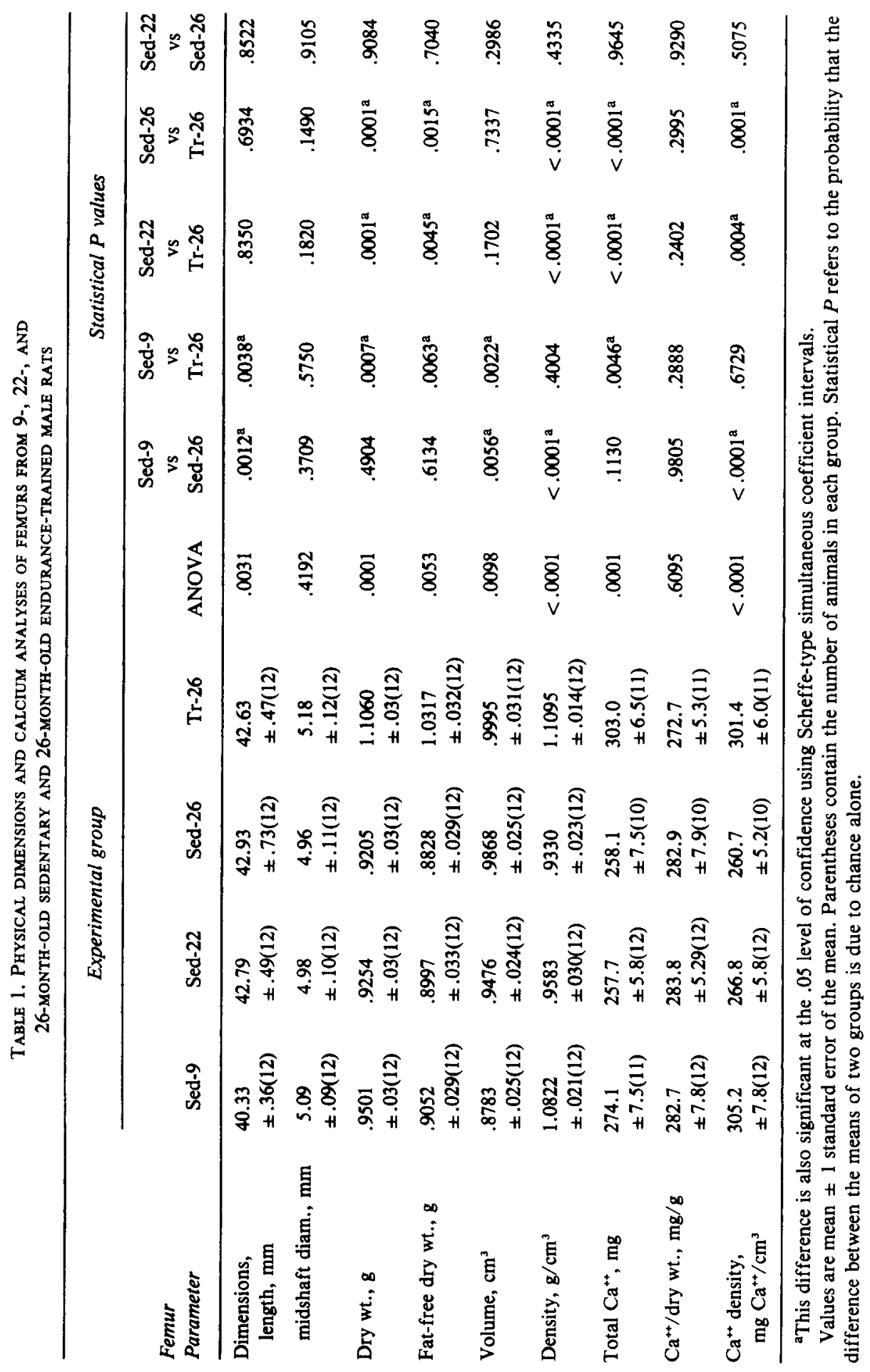




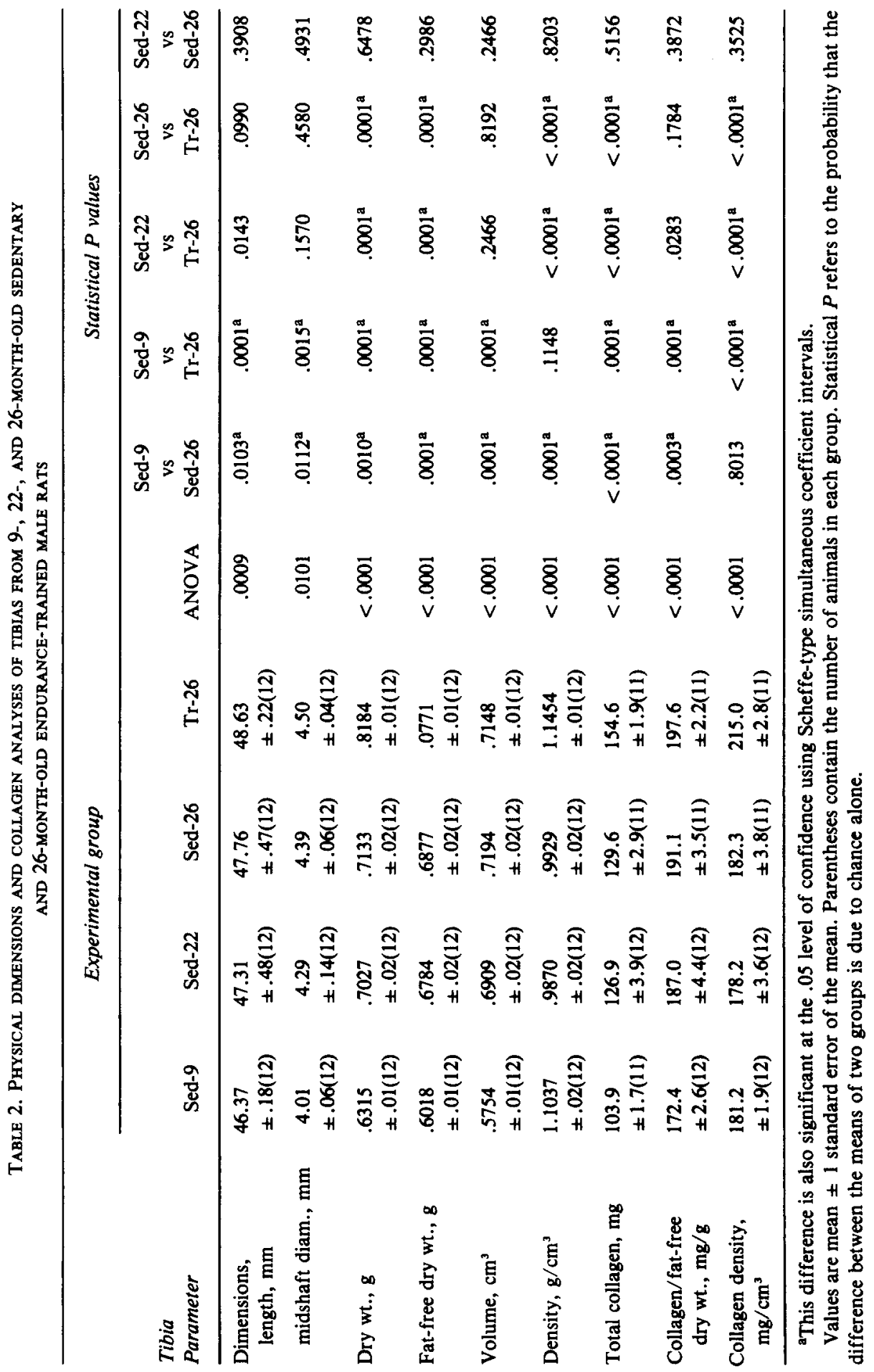


(Tables 1 and 2). Indications of the occurrence of osteopenia in these aging animals are the significant decreases in femur and tibia densities $\left(\mathrm{g} / \mathrm{cm}^{3}\right)$ (Tables 1 and 2 ) and the decrease in femur calcium density (Table 1), a reflection of the amount of calcium per volume of bone. This loss in bone mineral density occurred despite increases in bone volume, total collagen, and collagen content per fat-free dry weight and without an associated decrease in collagen density between 9 and 26 months (Table 2).

The data in Tables 1 and 2 thus indicate that the effects of exercise on the hind limb bones in these elderly rats were (a) an increase in dry weights and fat-free dry weights, (b) an increase in the total bone density to the level seen in the 9-month-old sedentary rat, (c) an increase in total calcium to levels greater than the 9-, 22-, and 26-month sedentary age groups, (d) a compensation for, or a reversal of, the loss of calcium density, due to senile osteoporosis, to a level not statistically different from 9-month-old sedentary animals, and (e) significant increases in total collagen and collagen densities.

\section{DISCUSSION}

The data from this study suggest that the decrease in hind limb bone weight with age is due primarily to loss of mineral content and not to the loss of organic bone material. The loss of total calcium and dry weight between 9 and 22 to 26 months are quantitatively similar when an adjustment is made for the molecular form of calcium in bone-hydroxyapatite. As the percentage increase in total collagen and bone volume were parallel, no change in collagen density was observed. Because of this increase in total collagen and diminished mineral content, the collagen per fat-free weight increased with age. This is in agreement with the report of Dequeker and Merlevede (1971) that collagen content of porous bone related to either fat-free weight or dry weight tends to increase with age. Thus, according to the present study, osteoporotic bone from aged animals has a lowered density when compared to 9-month-old animals, due primarily to loss of the mineral component, and an increased collagen fraction due to the greater loss of hydroxyapatite than to the collagen matrix.

Senile osteopenia appears to be a consequence of both an increased calcium demand due to negative calcium balance and loss of the calcium homeostasis of bone due to a break-down of regulatory mechanisms (Avioli, 1981). Failure to prevent the negative calcium balance inevitably results in substantial bone resorption, leading to low mass and high collagen concentrations. The present experiments demonstrate that net mineral loss does not occur in hind limb bones of physically active animals; to the contrary, total mass increases due to increases in both total collagen and minerals. Exercise thus appears to influence the formation of the connective tissue matrix essential for mineral deposition in bone formation. Exercise also stimulates the turnover of connective tissue in a variety of other tissues (Beyer, 1983).

Although the precise mechanism of bone loss in senile osteoporosis in not known, a number of processes have been implicated, including decreased intestinal and renal calcium absorption leading to a negative calcium balance, complex hormonal interactions, inactivity (Avioli, 1982), and the loss of calcium homeostasis due to degeneration of regulatory systems on the bone surface (Tonna, 1978; Tonna and Cronkite, 1964). Because endurance exercise appears to compensate for the loss of bone in the aged animals, an appropriate approach to the study of underlying metabolic bases for the prevention of osteoporosis may be to investigate such systems in animals adapting to endurance exercise. It has been reported that osteoblastic activity and population decrease dras- 
tically with advancing age (Tonna, 1978; Tonna and Cronkite, 1964). Observations of osteoblasts during endurance training in the elderly animal, therefore, may yield valuable information on control of osteoblastic activity, as well as its possible role in bone repair in the elderly.

A bone morphogenetic protein (BMP) that may regulate the differentiation of mesenchyme cells into cartilage and bone has been demonstrated (Urist et al., 1979) and found to be diminished in aged bone (Urist et al., 1981). This protein may be involved in the response of bone to exercise reported herein. Because the present study indicates that exercise increases bone density by stimulating matrix formation in partially demineralized bone and because BMP is assayed by its ability to induce osteogenesis by demineralized bone matrix (Syftestad and Urist, 1980), a study of the activity of BMP in the bones of exercising individuals may yield important information. These and other factors that affect bone have been reviewed recently (Simpson, 1984).

As Hayflick (1979) has suggested, a decline in proliferative potential is an innate, programmed property of all cells. One of the goals of those studying aging is to identify means of shifting the aging curve from a general decline to a more rectilinear shape. Many of the changes that accompany aging, at least in the laboratory rat and the human, are similar to those accompanying disuse atrophy (Bortz, 1982). The data reported herein and elsewhere suggest that a regular exercise program is able to reverse, or delay, some of the age-related functional declines, even if initiated late in the life of otherwise sedentary individuals. This is not to suggest, however, that cells remain responsive indefinitely to stimuli such as exercise because some evidence exists for a "threshold age" (Edington et al., 1972). Richardson and Cheung (1982) have suggested that with age there occurs a general decline in gene expression, translation, and transcription, resulting in a decrease in the response of the aged animal to stimuli and a lowering of induced enzyme synthesis. Although it appears that tissues of animals close to the end of their maximal life span are unresponsive to stimuli such as exercise (Steinhagen-Thiessen et al., 1980, 1981), those of somewhat younger animals are still able to reverse degenerative age-associated metabolic and structural changes. However, the question of the fraction of the life span of an animal that must remain in order for aging-associated degenerative changes to maintain responsiveness to repair stimuli is still unanswered. The data reported herein suggest that relatively mild endurance exercise, inititated in animals in which osteoporosis has progressed to a measurable level, may still reverse or compensate for this disabling, degenerative condition of old age. In a study of women averaging 81 years, exercise over a period of 3 years has been shown to slow the rate of bone loss and increase bone mineral content (Smith $e t$ $a l ., 1981 \mathrm{~b}$ ). Apparently, 81 years in the human and 22 months in the rat are not too late to start employing exercise to protect bones from the adverse effects of aging and the consequences of a sedentary lifestyle.

Bone loss is a well-recognized consequence of bed rest, limb immobilization, and loss of normal gravitational stimuli due to space travel (Smith, 1981; Montoye et al., 1980; Krølner and Toft, 1983; Smith et al., 1981a; Wronski and Morey, 1983). Data also exist demonstrating prevention of space travel-associated bone loss with appropriate exercise (Mack et al., 1967) as well as reversal of bone loss in elderly animals by exercise (Saville and Whyte, 1969; Nilsson and Westlin, 1971; Smith et al., 1976; Bell et al., 1980; Lanyon and Bourn, 1979; Krølner et al., 1983). For these reasons this non-invasive treatment, exercise, lacking the side effects of alternative drug therapy, should receive serious, widespread consideration. A plea for more information in this area through research on humans has been published (Holloszy, 1983). 
It should be of interest to note that other measurements on the rats used in this study or others similarly trained indicate that gastrocnemius muscle myoglobin (Beyer and Fattore, 1984), flavin, and oxidative enzymatic capacities (Beyer et al., 1984) are all increased in the trained aged group to levels equal to, or greater than, those of the 9-month-old sedentary animals. In addition, myocardial function and aerobic energy metabolism were improved (Starnes et al., 1983a) and coenzyme $Q$ concentrations increased (Beyer and Starnes, 1985) when compared to age-matched sedentary animals.

Acknowledgments - We thank Mr. Steven Goodman of The University of Michigan Museum of Zoology for making the domestic beetle, Dermestes vulpinus, available to us; Dr. Alex S. Tompa for instruction and use of his Atomic Absorption Spectrophotometer; Ms. Sheila Cameron for her patience while training the elderly rats to run; Mr. Rollin Gruschow for meticulous care of our aging rat colony; and the Cutcheon Fund of The University of Michigan Honors Program and the Michigan Heart Association for financial support. We thank Ms. Kathleen D. Timberlake and Drs. Richard C. Adelman, Stanley M. Garn, Henry J. Montoye, and Everett L. Smith for reviewing an early version of the manuscript prior to submission for publication and Ms. Patricia Wolfe and Ms. Margaret Madouse for preparing its several versions. We also thank Professors Kenneth Guire and George Estabrook for invaluable help with the statistical analysis.

\section{REFERENCES}

Albanese, A.; Edelson, A., Lorenze, E.; Wein, E. (1969) J. Amer. Geriat. Soc. 17: 142-154.

Alffram, P.; Bauer, G. (1962) J. Bone. Jt. Surg. 44A: 105-114.

Arnold, J.; Bartley, M.; Tont, S.; Jenkins, D. (1969) Clin. Orthop. 49: 17-38.

Aviou, L.V. (1977) In: Avioli, L.V.; Krane, S.M., eds. Metabolic bone disease, Vol. 1. New York: Academic Press, pp. 307-370.

Aviou, L.V. (1981) Federation Proc. 40: 2418-2422.

Aviolı, L.V. (1982) In: Peck, W.A., ed. Bone and mineral research annual 1. Amsterdam: Elsevier, pp. 264-308.

Bell, R.R.; Tzeng, D.Y.; DRAPER, H.H. (1980) J. Nutr. 110: 1161-1168.

BEYER, R.E. (1983) In: Borer, K.T.; Edington, D.W.; White, T.P., eds. Frontiers of exercise biology. Champaign, IL: Human Kinetics Publishers, pp. 85-99.

Beyer, R.E.; FatToRe, J.E. (1984) J. Gerontol. 39: 525-530.

BeYer, R.E.; Starnes, J.W. (1985) In: Stone, H.L.; Weglicki, W.B., eds. Advances in myocardiology (Pathobiology of Cardiovascular Injury), Vol. 7. Boston, MA: Martinus Nijhoff Publ. Co., pp. 489-511.

Beyer, R.E.; Starnes, J.W.; Ednngton, D.W.; Lipton, R.J.; Compton, R.T., III; Kwasman, M.A. (1984) Mech. Ageing and Devel. 24: 309-323.

Bortz, W.M., II. (1982) J. Am. Med. Assoc. 248: 1203-1208.

Brewer, V.; Meyer, B.M.; Keele, M.S.; Upton, S.J.; Hagan, R.D. (1983) Med. Sci. Sports Exer. 15: 445-449.

Cassuccio, C. (1962) J. Bone Jt. Surg. 44B: 453-463.

Chalmers, J. (1970) J. Bone Jt. Surg. 52B: 667-675.

Dequeker, J., Merlevede, W. (1971) Biochim. Biophys. Acta 244: 410-420.

Edington, D.W.; Cosmas, A.C.; McCafferty, W.B. (1972) J. Gerontol. 27: 341-343.

Farrar, R.P.; Martin, T.P.; ARdies, C.M. (1981) J. Gerontol. 36: 642-647.

GARN, S.M. (1970) The earlier gain and later loss of cortical bone. Springfield, IL: Charles C Thomas.

Garn, S.; Rohmann, C.; Pao, E.; Hull, E. (1966) In: Wedon, G.; Neumann, W.; Jenkins, D., eds. Progress in development of methods in bone densitometry. Washington, DC: NASA, SP-64, pp. 187-193.

Garn, S.; Rohmann, C.; Wagner, B. (1967) Federation Proc. 26: 1729-1736.

Garn, S.; Rohmann, C.; Wagner, B.; Davillia, G., Ascoli, W. (1969) Clin. Orthop. 65: 51-60.

Goldsmith, N.; Johnston, J.; URY, J.; Vose, G.; Colbert, C. (1971) J. Bone Jt. Surg. 53A: 83-100.

HAYFLICK, L. (1979) Aging 8: 3-19.

Holloszy, J.O. (1983) Med. Sci. Sports Exerc. 15: 1-5.

KenNy, A.D.; ToEPel, W.; Schour, I. (1958) J. Dent. Res. 37: 432-443.

Krølner, B.; Toft, B. (1983) Clin. Sci. 64: 537-540. 
KRøLner, B.; Toft, B.; Nielsen, S.P.; TøNdervold, E. (1983) Clin. Sci. 64: 541-546.

LANYON, L.E.; Bourn, S. (1979) J. Bone Jt. Surg. 61A: 263-273.

LeRoy, E.C. (1967) Adv. Clin. Chem. 10: 213-253.

Mack, P.; LaChance, P.; Vose, G.; Vogt, F. (1967) Amer. J. Roent. 100: 503-511.

Mazess, R.B.; Whedon, G.D. (1983) Calc. Tissue Internat. 35: 265-267.

MCCafferty, W.B., Edinoton, D.W. (1974) Gerontologia 20: 44-46.

McMillan, D.E. (1978) Aerosp. Med. 39: 849-854.

Mryada, D.S.; TAPPEL, A.L. (1956) Anal. Chem. 28: 909-910.

Montoye, H.J.; McCabe, J.F.; Metzner, H.L.; Garn, S.M. (1976) Human Biology 48: 599-610.

Montoye, H.J.; Smth, E.L.; Fardon, D.F.; Howley, E.T. (1980) Scand. J. Sports Sci. 2: 26-37.

Munson, P.L.; Iseri, O.A.; Kenny, A.D.; Cohn, V.; Sheps, M.C. (1955) J. Dent. Res. 34: 714-721.

Neuman, R.E.; Logan, M.A. (1950) J. Biol. Chem. 184: 299-307.

Nusson, B.E.; Westurn, N.E. (1971) Clin. Orthop. Rel. Res. 77: 179-182.

OHNishi, S.; Ebashi, S. (1964) J. Biochem. (Tokyo) 55: 599-603.

Oyster, N.; Morton, M.; Linnell, S. (1984) Med. Sci. Sports Exerc. 16: 44-50.

Richardson, A; Cheuno, H.T. (1982) Life Sci. 31: 605-613.

Rose, G. (1970) In: Barzel, U.S., ed. Osteoporosis. New York; Grune \& Stratton, pp. 123-132.

Saville, P.D.; Whyte, M.P. (1969) Clin. Orthop. Rel. Res. 65: 81-88.

Simpson, E. (1984) Trends Biochem. Sci. 9: 527-530.

SMith, D.M.; Khari, M.R.A.; Norton, J.; Johnson, C.C. (1976) J. Clin. Invest. 58: 716-721.

SMIth, E.L. (1981) In: Serfass, R.C.; SMITH, E.L., EDs. Exercise and aging: The scientific basis. Hillside, NJ:

Enslow Publishers, pp. 179-186.

Smith, E.L., JR.; Reddan, W.; Smith, P.E. (1981a) Med. Sci. Sports Exerc. 13: 60-65.

Smtr, E.L.; Sempos, C.T.; Purvis, R.W. (1981b) In: Serfass, R.C.; Smith, E.L., eds. Exercise and aging:

The scientific basis. Hillside, NJ: Enslow Publishers, pp. 59-87.

SMrTH, R. (1967) Federation Proc. 26: 1737-1746.

Starnes, J.W.; Beyer, R.E., Edington, D.W. (1983a) Am. J. Physiol. 245, (Heart Circ. Physiol. 14): H560H566.

Starnes, J.W.; Ednngton, D.W.; Beyer, R.E. (1983b) J. Gerontol. 38: 660-665.

Steinhagen-Thiessen, E.; Reznik, A.; Hnz, H. (1980) Mech. Ageing Dev. 12: 231-236.

Steinhagen-Thiessen, E.; Reznix, A.; Hnz, H. (1981) Mech. Ageing Dev. 16: 363-369.

Syftestad, G.T.; URist, M.R. (1980) Proc. Soc. Exper. Biol. Med. 163: 411-415.

TonNA, E.A. (1978) J. Gerontol. 33: 163-177.

TonnA, E.A.; CRonkite, E.P. (1964) Lab. Invest. 13: 161-171.

URIST, M. (1962) Ann. Rev. Med. 13: 273-286.

Urist, M.R.; Conover, M.A.; Ltetze, A.; Triffitt, J.T.; Delange, R. (1981) In: Cohn, D.; Talmage, R.; Mathews, J.L., eds. Proc. of VII Internatl. Conf. on Calcium Reg. Hormones. Amsterdam, the Netherlands: Excerpta Medica.

Urist, M.R.; Mikulski, A.; Lietze, A. (1979) Proc. Natl. Acad. Sci. U.S.A. 76: 1828-1832.

Williams, J.A.; Wagner, J.; Wasnich, R.; Henbrun, L. (1984) Med. Sci. Sports Exerc. 16: 223-227.

Wronski, T.J.; MoreY, E.R. (1983) Med. Sci. Sports Exerc. 15: 410-414. 